\title{
Moral Hazard, Land Fertility and Sharecropping in a Rural Area of the Philippines
}

\author{
Pierre DUBOIS \\ INRA, Toulouse* \\ First Version: April 1998 \\ This Version: October $2000^{\dagger}$
}

\begin{abstract}
Introducing concerns about land fertility for landlords in a Principal-Agent model of sharecropping with moral hazard, we show that the optimal contract under limited commitment reflects a trade-off between production and land quality maintenance. Using Philippines data, a model where the leasing out and contract choices are simultaneous is estimated and avoids the selectivity bias of observed contracts. Landlords prefer to use more incentive contracts for more fertile plots and less incentive ones when crop choices induce land overuse. Empirical tests reject the model of pure risk sharing in production and show the interest of taking land quality maintenance into account.

Key Words: sharecropping, moral hazard, incentive contracts, land value, soil conservation, empirical contract theory.
\end{abstract}

JEL Classification: D23, D82, Q12, Q15, Q24.

\footnotetext{
*Address:

University of Toulouse I, Manufacture des Tabacs-Bât.F-INRA, 21 allée de Brienne, 31000 Toulouse, France e-mail: dubois@toulouse.inra.fr

$\dagger$ Acknowledgments: I am indebted to Bruno Jullien and Thierry Magnac for numerous discussions. Data were provided by the International Food Policy Research Institute and I thank Howarth Bouis for his help. The paper was mostly written at CREST to which I am grateful for financial support during my Ph.D. I especially thank A. Foster, S. Lambert and B. Salanié for careful comments and P. Rey for comments on a companion paper presented at an INRA-IDEI workshop in Toulouse. I thank J.P. Amigues, A. Banerjee, M. Buchinsky, D. Fougère, A. de Janvry, E. Ligon, D. Margolis, K. Otsuka, J. Pender, A. Quisumbing, S. Roux, E. Sadoulet and M. Visser for their comments, the seminar participants at IFPRI, CREST, Boston University, Brown University, Concordia University, CREST-LEI, INRA ESR Toulouse, Université de Montréal, North Carolina State University, University of California at Berkeley, 1998 Journées de Microéconomie Appliquée (Pointe-à-Pitre), 1998 Econometric Society European Meeting (Berlin), 1998 European Economic Association Conference (Berlin), the Stanford Institute for Theoretical Economics, two anonymous referees and co-editor Mark Rosenzweig. All remaining errors are mine.
} 


\section{Introduction}

The efficiency of share tenancy has mainly been studied in a static framework. Stiglitz (1974) points out that share contracts are second best choices because they result from a trade-off between incentives to work and risk sharing. In the transaction cost approach (Allen and Lueck, 1993), the type of agricultural contracts are determined by contracting costs. Yet, Johnson (1950) wrote: "When a man sells a bushel of wheat, he has no interest in the use to which the wheat is put and is consequently willing to sell to the highest bidder. However, when a man sells the use of land, he has a real interest in how the land will be used. Consequently, the choice of tenant is never made without considering what the impact of the tenancy will be upon the value of the asset." It seems relevant for the landlord to take into account the dynamics of land fertility. When this dynamics is explicitly formalized, it remains to be proven that static arguments about efficiency are still valid. In a dynamic model we might have to derive the way incentives are designed according to the management of land fertility.

In most share-tenancy models the landowner's objective is to maximize expected utility which depends on net benefit, effort supply and the contract shape (Stiglitz, 1974, Eswaran and Kotwal, 1985, Singh, 1989, or Otsuka, Chuma and Hayami, 1992). Among the papers adopting a dynamic framework, none allows for a dynamic dependence of land fertility on cultivating choice. Dutta, Ray, Sengupta (1989) analyze the efficiency problem when the relationship is infinitely repeated and the landlord uses threats of eviction. Bose (1993), shows how infinitely long fixed rent contracts interlinked with credit agreements between a landowner and a peasant bring a more efficient allocation of resources when investment is needed. Otsuka, Chuma and Hayami (1993) examine long term agrarian contracts to show that share tenancy is more efficient than fixed wage permanent labor. Other models take into account some aspects of land characteristics and land fertility with a transaction cost approach. Allen and Lueck (1992) analyze the choice between cash rent and crop share contracts; they argue that a share contract can curb the farmer's incentive to exploit land attributes. Bardhan (1984, ch. 7), Braverman and Stiglitz (1986) show how production sharing and cost sharing give more efficient incentives on a fertilizer input and a non observable labor effort. Bardhan (1984, ch. 8) shows with a two period model the trade-off between production incentives, enhanced in first period by a dismissal threat from the landowner, and land improvement incentives decreasing with a more powered contract.

An important issue modelled here is that agricultural activity during a crop season affects 
future production because land fertility is governed by an investment function depending on the past fertility level and the cultivator's effort. Agent's actions are not observable to the Principal and contracts are incomplete because they cannot be contingent on land fertility. The landowner's intertemporal utility is defined as a function of all future net benefits due to his property right. Considering a sequence of short term contracts, the shape of the utility of the Principal is markedly different from what results in standard moral hazard models, since it includes the value of land. The repeated moral hazard theory does not consider this case because in most of them Agent's actions don't modify future production technology (Rogerson, 1985, Lambert, 1983). Fudenberg, Holmstrom and Milgrom (1990) and Malcomson and Spinnewyn (1988), in a repeated moral hazard relationship, study the possibility to implement long term contracts, which are Pareto superior to short term agreements (Radner, 1985, Rubinstein and Yaari, 1983), by sequences of spot contracts. We know that short term renegotiable contracts achieve long run efficiency when there is no informational asymmetry at contracting dates (Rey and Salanié, 1990, 1996) but spot contracting may fail to optimally smooth agent's consumption. Here, we consider different informational conditions because contracts are incomplete and last for one period in an environment where long term full commitment is not credible.

We derive the optimal second best linear contract which is different from Stiglitz (1974). For example, if risk neutrality is assumed, the optimal contract is not a fixed rent contract but a sharecropping one. Low powered incentives (in the sense of Williamson, 1985) come from the presence of efforts leading to fertility damages though they are productive in the short term. As in Baker (1992), the gap between the Principal's objective and the Agent's performance measure leads to distortions in efforts. We show how the optimal sharing rule depends on land fertility, production and land investment functions (and Agent's risk aversion). Then we obtain empirically testable implications of the model relating the choice of contract and land value when the production effort can reduce the land fertility because of land overuse. Allen and Lueck $(1993,1996)$ show on American data how transaction cost considerations could explain the determinants of choices between cash rent and crop share contracts. The idea of the transaction cost approach telling that the tenant and the landlord have different interests in the exploitation of land attributes arises endogenously in our model. We implement empirical tests between predictions of the pure risk sharing model (Stiglitz, 1974) and the present dynamic model using Philippines data. The empirical study shows that fixed rent contracts are preferred to sharecropping for most fertile plots and that sharecropping is preferred when crops inciting 
to land overuse, such as corn, are grown. Our results seem to be robust to various specification tests, in particular with respect to the presence of heterogeneity between landowners. A main contribution of the paper is also that, unlike empirical studies on share tenancy, we avoid the selection bias of observed contracts (selected upon participation), by estimating the simultaneous choice to lease out and of type of contract. A recent contribution by Ackerberg and Botticini (2000) underlines a related issue concerning the potential endogenous matching of landlords and tenants in the contractual relationship.

Section 2 presents the micro-economic model. In section 3, the empirical study implements tests of some predictions of the model. In section 4, we conclude and comment on the development policy implications of our empirical results. Actually, according to our model, reforms of contractual institutions may have some significant impact on land qualities. In addition to the usual need for insurance of rural households, provided by sharecropping, our model suggests that the impossibility to commit credibly to long term agreements may also justify less incentive contracts to minimize land overuse incentives. Moreover, we discuss how landowners' decisions to lease out land may be affected by the set of possible contracts used which influence the access to land for tenants through the land rental market. The appendix is in section 5 .

\section{A dynamic model of contracting}

In this section, we present a Principal-Agent model with moral hazard taking into account the endogenous evolution of land fertility in share-tenancy.

\subsection{Production, information and preferences}

The agricultural production function is assumed to be linear homogenous with respect to land area (as generally admitted, Otsuka, Chuma and Hayami, 1992). For a fixed amount of land, $y_{t}$ is the agricultural output in period $t, e_{t}$ an index of peasant's work effort defined as the efficient labor time (decision variable) ${ }^{1}$, and $x_{t-1}$ an index of land fertility at the end of period $t-1$ (state variable). The agricultural production function $f$ is such that $y_{t}=\nu_{t} f\left(x_{t-1}, e_{t}\right)$ where $\nu_{t}$ is a multiplicative positive random variable with mean one representing weather uncertainty. Dynamics of land fertility are described by an investment function $x_{t}=\varepsilon_{t} g\left(x_{t-1}, e_{t}\right)$ where $\varepsilon_{t}$ is a mean one positive random variable which represents weather shocks. The general form of $g$ includes cases where $x_{t}$ has a time invariant component related to a particular land characteristic.

\footnotetext{
${ }^{1}$ It is assumed that the labor inputs whether family labor or hired in labor are aggregable in a single index variable $e$ and that their cost can be expressed as a function of $e$ only.
} 
We hereafter do the following assumption:

Basic Assumption $f(.,$.$) is increasing in both arguments and globally concave. g(.,$.$) is$ increasing in $x$, non-increasing in $e$ and globally concave.

We study the relationship between a landowner (Principal) and a peasant (Agent) who rents land under a contractual arrangement. The production is observable and verifiable. Agent's actions are unobservable by the Principal, the source of moral hazard because monitoring costs are assumed prohibitively high (Otsuka, Chuma and Hayami, 1992). We assume that land fertility has no contractible value because it is not verifiable though observable which is consistent with the casual observation shows that contracts are never complete and do not include conditions on land fertility. At each crop season, the landowner can contract with a tenant for the current period but cannot commit himself to more than one period. Though nothing prevents him to sign again a contract with the same tenant, contracts are signed for one season only ${ }^{2}$. The impossibility to commit is a simplifying assumption justified in the empirical application by the observation of a very high contracting turn over in the Bukidnon area studied ${ }^{3}$.

According to the contract signed, the Principal pays the Agent $\tau_{t}\left(y_{t}\right)$ at the end of crop season $t$. Let $U\left(\tau_{t}\left(y_{t}\right)\right)-C\left(e_{t}\right)$ and $y_{t}-\tau_{t}\left(y_{t}\right)$ denote the Agent's and Principal's instantaneous utility functions. $C($.$) (increasing, convex and twice differentiable) is the cost of effort or its disutility$ and $U($.$) a Von Neumann Morgenstern utility function increasing and concave. The Principal$ is risk neutral. Agent's utility is separable between income and leisure and his exogenous reservation utility is $\bar{U}$. We don't model explicitly the fact that households could be both landlords and tenant with respect to different plots, this happen very seldom in the data and we assume abusively and for simplicity that these decisions are independent.

\subsection{Intertemporal optimization and land value}

Assuming that the decision criterium of landowners depends on the value of the expected profits derived from land exploitation, we first study the property and determinants of the value of income streams. This will help us draw testable implications on land tenure choices by landowners according to the land value (an information potentially available in agricultural data sets and

\footnotetext{
${ }^{2}$ Though Pareto superior, a long term contract where parties can commit would require the tenant's payment to be contingent to current and past performances ("memory effect" shown by Rogerson, 1985, Chiappori, Macho, Rey, Salanié, 1994). These contracts require that past productions be recorded and verifiable in the future.

${ }^{3}$ In the case of Bukidnon, an hypothesis is that the threat of implementation of the land reform may have destroyed long term commitment credibility in the landowners-tenants relationships. But the test of this hypothesis seems difficult and beyond the scope of this paper.
} 
actually in the Philippines data used).

The Principal designs and proposes a contract that maximizes his intertemporal utility (additively separable with discount factor $\delta \in\left[0,1[)\right.$ under the Agent's incentive compatibility $\left(I C_{t}\right)$ and individual rationality $\left(I R_{t}\right)$ constraints:

$$
\begin{aligned}
v_{0}(x)= & \underset{\tau_{t}(.)}{\operatorname{Max}} E_{\nu_{t}, \varepsilon_{t}} \sum_{t=0}^{\infty} \delta^{t}\left[y_{t}-\tau_{t}\left(y_{t}\right)\right] \\
& \text { s.t. } \forall t \geq 0,\left\{\begin{array}{l}
E U\left(\tau_{t}\left(y_{t}\right)\right)-C\left(e_{t}\right) \geq \bar{U} \quad\left(I R_{t}\right) \\
e_{t} \in \arg \max _{e} E U\left(\tau_{t}\left(y_{t}\right)\right)-C(e) \quad\left(I C_{t}\right)
\end{array}\right.
\end{aligned}
$$

The landowner's alternative to sell the land instead of continuing to lease out can be ruled out if we assume that the land sales market is almost completely inactive because of liquidity constraints of potential buyers and imperfect financial markets ${ }^{4}$. As $\left(I R_{t}\right)$ and $\left(I C_{t}\right)$ are period specific, random terms and reservation utility assumed stationary, the value function $v$ is a solution to the "Bellman equation" in $w($.$) :$

$$
w(x)=\underset{\tau(.)}{\operatorname{Mat.}(I C),(I R)}\{[E[y-\tau(y)]+\delta E w(z)\}
$$

where $z=\varepsilon g(x, e)$ and $v(z)$ represents the optimal value that the Principal can get at the beginning of next period when land quality is equal to $z$. As the tools of contract theory (see Hart and Holmstrom, 1987) do not provide enough characterization of the optimal contracts to derive formal properties of $v($.$) (in particular concerning its monotonicity), we will restrict$ the analysis to linear contracts $^{5}$ of the form $\tau(y)=a y+b$ with $a \geq 0$ being the share of production promised to the tenant. The value function properties will be helpful to derive testable implications of landowners' choices according to the land value, observed in the data, rather than an unobservable fertility index. With perfect information, one can show easily that the land value is an increasing and concave function of fertility $x$, and under imperfect information (proof in appendix 5.1):

Proposition 2.1. When the Agent is risk neutral, the land value function is increasing and concave.

With risk neutrality, the land value endogenously derived in the model is equal to the first best one where the Agent's effort is enforceable. When the Agent is risk averse, comparative

\footnotetext{
${ }^{4}$ The Principal's objective will not be modified if land prices equal exactly the long term value provided to the owner by agricultural contracts.

${ }^{5}$ We could call upon bounded rationality to justify this behavior. But, simple incentive schemes like sharing rules are generally prevalent in the economy. Hart and Holmstrom (1987) argue that it can be caused by prohibitive costs of writing intricate contracts but also by a need for robustness with respect to other possible Agent's choices. Holmstrom and Milgrom (1987) show that linear contracts are optimal in a continuous time framework when errors are normal and the Agent has constant absolute risk aversion.
} 
statics are more complicated. Then, we choose simple and plausible sufficient assumptions to derive interesting testable implications.

Assumption 1a The ratio $f_{e} / f$ is weakly increasing with fertility $\left(\frac{\partial}{\partial x}\left(f_{e} / f\right) \geq 0\right)$.

Assumption 1b The ratio $f_{e} / f$ is constant with fertility $\left(\frac{\partial}{\partial x}\left(f_{e} / f\right)=0\right)$.

Assumption 2 The land fertility and effort are complementary in production $\left(f_{e x} \geq 0\right)$.

Assumption 3 The marginal negative impact of effort on fertility decreases with the fertility level $\left(g_{e x} \geq 0\right)$.

The production functions of the Cobb-Douglas form satisfy the assumptions $1 a, 1 b$ and 2 . The assumption 3 says that the marginal negative effect of effort on fertility is constant or decreasing with the fertility level. Less fertile plots are also more fragile.

Assumption 4 Third order effects compared to second order ones are negligible in comparative statics.

This approximation assumption is not always needed in the following of the paper but sometimes helps exhibiting simple cases. The proof of the proposition is in appendix 5.3.

Proposition 2.2. If the Agent is risk averse, under assumptions $1 a, 2,3,4$ or $1 b, 2,3$ the land value function is increasing and concave.

\subsection{Optimal incentives}

The Principal's objective is to maximize the expected sum of the current period utility and the future discounted land value i.e. $(1-a) y-b+\delta v(z)$ where $v($.$) is the solution of the$ Bellman equation. It is then easy to show that the first best contract consists in enforcing the optimal effort level $e^{*}$ defined by the following first order condition $f_{e}-U^{-1^{\prime}}\left(\bar{U}+C\left(e^{*}\right)\right) C_{e}+$ $E\left[\varepsilon \delta v^{\prime}\right] g_{e}=0^{6}$ and in paying the Agent a fixed wage leaving him with his reservation utility. As usual, full insurance is provided to the risk averse Agent while the risk neutral Principal bears all the risk. In the case of imperfect information on Agent's action, we prove in appendix 5.2 that Pareto efficiency is achieved if and only if the Agent is risk neutral and that:

\footnotetext{
${ }^{6}$ It is sufficient because $v$ is increasing concave. The first best effort may be zero in which case the first order condition is an inequality and the optimal use of land is to leave it fallow.
} 
Proposition 2.3. The slope of the second best optimal contract verifies ${ }^{7}$ :

$$
a^{*}(x)=1+E \varepsilon \delta v^{\prime} \frac{g_{e}}{f_{e}}-\left(1-\frac{E \nu U^{\prime}}{E U^{\prime}}\right) \frac{f}{e_{a} f_{e}}
$$

We get a trade-off between production incentives, fertility incentives and sharing of production risk. The first term equals one and corresponds to the optimal share when the tenant is risk neutral and fertility is not worth for the landowner (fixed rent contract). The second term characterizes the trade-off between incentives in production and incentives in investment in fertility. The third term comes from the trade-off between production incentives and risk sharing. Since 1- $E \nu U^{\prime} / E U^{\prime}>0$ ( $U$ concave), the risk sharing term reduces the value of $a^{*}$, and the tenant bears less risk (appendix 5.2 shows that $e_{a}>0$ in the risk neutral case, but with risk aversion, income effects make comparisons more difficult).

As effort has opposite influences on production and on land fertility, the optimal contract has low powered incentives even with risk neutrality (share smaller than one) and is not a fixed rent as usual (Stiglitz, 1974, Newbery and Stiglitz, 1979, Otsuka, Chuma and Hayami, 1992) but a share contract with a fixed part maintaining the Agent to his reservation utility level. The risk sharing argument is not necessary to explain share contracts because investment in fertility can motivate them. The optimal contract depends on land quality which may explain the different patterns of contracts even without heterogeneity in preferences. It explains why a landowner may decide to self cultivate or lease out land plots and why he chooses different contracts for different plots.

\subsection{Decision to lease out}

To analyze landowner's choice to lease out a plot of land, we compare the value of delegation (leasing out) and of self cultivation for the landowner ${ }^{8}$.

- Difference between the first best $\left(v_{f b}\right)$ and the second best value $\left(v_{s b}\right)$ of the land leasing: Efficiency loss due to the Agent's risk aversion

If the agent is risk neutral, the second best land value equals the first best value. Otherwise, the second best value is lower than the first best one because of the risk sharing trade-off. With assumptions $1 b, 2$ and 3, we have the following proposition (proof in appendix 5.4):

\footnotetext{
${ }^{7}$ With a risk averse Principal (utility function $\left.V\right): a^{*}=1+\frac{E \varepsilon v^{\prime}}{E \nu V^{\prime}} \frac{g_{e}}{f_{e}}-f\left(1-\frac{E \nu U^{\prime} E V^{\prime}}{E U^{\prime} E \nu V^{\prime}}\right) / e_{a} f_{e}$.

${ }^{8}$ Of course, we compare the value of each choice (self cultivation or delegation) with a given value function of future fertility that would integrate the different choices. The value of each option separately are increasing concave. We need to prove that the value function integrating the possibility to lease out or not is also increasing concave. It is more difficult unless we allow for mixed strategies in the complete program.
} 
Proposition 2.4. Under imperfect information, when the Agent is risk averse and the second best effort is lower than the first best (i.e. when higher incentives increase effort), the efficiency loss increases with land fertility.

The second best effort is likely to be lower than the first best since equation (3) shows that the risk sharing term will generally lead to less incentive contracts and therefore to a smaller level of effort if the utility function is such that increasing incentives actually leads to increase the implemented effort (which is the case generally considered in the share tenancy literature). - Difference in the land valuation between leasing out and self cultivation: Gap between the valuations of fertility for self cultivation and delegation due to the asymmetry in the cost of effort between Principal and Agent

An implicit assumption of the Principal-Agent model is that the delegation of production is worth for the Principal because its cost of effort is sufficiently larger than that of the Agent. We also assume that a landowner can eventually hire laborers to work on his land but that he then has to monitor them (otherwise they provide no effort) which is costly to the landowner. Modelling explicitly this assumption, we compare the valuation of self cultivation by the landowner $\left(v_{s c}\right)$ and the valuation of leasing out in the risk neutral case $\left(v_{f b}\right)$.

Assumption 5 The marginal cost of effort of the landowner is larger than that of the tenant.

Proposition 2.5. Under assumptions 2, 3 and 5, the difference between the value of leasing out land to a risk neutral agent and the value of self cultivation is increasing with fertility.

This proposition (proved in 5.5) means that the difference between the value of land when the landowner delegates its use to a risk neutral peasant for whom effort is less costly and the value of self cultivation is increasing with fertility. Under risk neutrality the first best is achieved but as fertility increases the optimal effort increases and becomes more and more costly for the landowner in comparison to the peasant.

Assume that a landowner chooses to lease out if the difference $v_{s c}-v_{s b}$ between the value of self cultivation $\left(v_{s c}\right)$ and the value of land delegation to a risk averse Agent $\left(v_{s b}\right)$ is lower than some unobserved landowner specific effect $\varepsilon$ (a kind of fixed cost), randomly distributed with cumulative distribution function $F$. The probability that a landowner leases out a plot of land is $d(x)=F\left(v_{s c}(x)-v_{s b}(x)\right)$ and then $d^{\prime}(x)$ is of the sign of $v_{s c}^{\prime}(x)-v_{s b}^{\prime}(x)$. By propositions 2.4 and $2.5, v_{s c}^{\prime}(x)-v_{f b}^{\prime}(x)<0$ and $v_{f b}^{\prime}(x)-v_{s b}^{\prime}(x)>0$ (except in the particular case where the risk averse 
Agent supplies a higher effort than in the first best). The probability of delegation can increase or decrease with land fertility according to which of both terms dominates. It decreases when the efficiency loss of delegation dominates the valuation gap driven by the difference in effort cost between both parties. In this case, the landowner's preference to self cultivate increases even if it is more costly for him because the efficiency loss of the delegation is too high.

In addition, when the Agent is risk neutral, $v_{s c}^{\prime}(x)-v_{s b}^{\prime}(x)=v_{s c}^{\prime}(x)-v_{f b}^{\prime}(x)<0$, the probability of delegation for a plot of land increases with its fertility (this prediction does not depend on whether the landowner cares about future fertility). The empirical study of the probability of delegation (leasing out) with respect to the land value can then provide an empirical test of the presence of risk aversion.

\subsection{Predictions and testable implications}

It seems important to test if the inclusion of fertility dynamics in the share-tenancy model is empirically relevant? The correlation between contract incentives and land value could behave according to the existing canonical model of Stiglitz (1974). The complete comparative statics for the compared predictions are in appendix 5.6 and summarized in the following).

First, the optimal incentives of the contract depend on the possibility of land overuse and on its fertility level. This prediction depends on the technological assumptions made on $f$ and $g$ and in particular on the fact that effort has a negative effect on fertility $\left(g_{e}<0\right)$. In the case where effort is fertility neutral $\left(g_{e}=0\right)$ then the predictions are exactly the same as that of the pure static risk sharing model (à la Stiglitz). This will be important in the empirical tests since technological effects across crops may be different.

Under risk neutrality, sharecropping is optimal and the optimal share of production going to the tenant is increasing with land fertility. Actually, with some technical conditions or simply if fertility and labor are separable or substitutes in the production function (which is the case for Cobb-Douglas functions) and if $g_{e x} \geq 0$ (meaning that the marginal negative impact of effort on fertility decreases with the fertility level, it can be seen as a formal consequence of fragile lands which can be more damaged than better ones), then $a($.$) will be increasing { }^{9}$. Finally, if the tenant is risk averse (for example with Constant Absolute Risk Aversion utility), we show that the optimal incentives are likely to decrease with land fertility in the pure risk sharing

\footnotetext{
${ }^{9}$ When $g_{e x}<0, a($.$) will be increasing if the value function is sufficiently concave so that the marginal negative$ effect of effort on the land value decreases in absolute value with the fertility level.
} 
mode ${ }^{10}$. Optimal incentives increase with land fertility if the production/investment trade-off, due to the marginal land value influence, dominates the risk sharing trade-off. The probability that a landowner leases out a plot of land can be increasing or decreasing with its fertility level but is increasing if the Agent is risk neutral.

\section{TABLE 1 HERE}

The Table 1 shows the predictions on the optimal choices (leasing out and contract) according to $x$ which are the same with respect to land value since we showed that it is an increasing function of $x$ in our structural model. The landowner compares the value of delegation with the maximum value of delegating by sharecropping or by fixed rent. If a landowner decides to lease out, it can be through a sharecropping contract or a fixed rent contract. In this simultaneous choice framework, we of course don't observe what was the preferred form of contract of a landowner who decided not to lease out, but this can be accounted for in the econometrics. These predictions on the determinants of the joint choice allow to perform tests between the competing models and to determine which of the 4 alternatives best rationalizes the data. As is generally implicitly done in most empirical studies, we assume that tenants' preferences are homogeneous because we don't observe their characteristics in the data.

It is worth noting that we derived cross sectional predictions from our dynamic model in order to check whether empirical evidence supports it. However, the importance of dynamics, like cycles, in the decisions to leave land fallow is not ruled out. The optimal tenurial-cultivation choice (sharecropping or fixed rent if the landowner decides to lease out and own cultivation or leaving land fallow otherwise) depends on the fertility level which changes over time. As fertility can increase or decrease from one period to the other, it can give rise to different schemes of fertility and land tenure dynamics. The model is able to generate fertility cycles and cyclical patterns of land allocation and fallow. It is commonly admitted that leaving land fallow is generally intended to let the soil rest when fertility is low. The model gives a possible rationale to the observed cyclical behaviors thanks to fertility dynamics (Dubois, 1998b).

\section{Empirical evidence from a rural area of the Philippines}

The main relevant question concerns the empirical relevance of our dynamic model, and whether it can be distinguished from the canonical framework (Stiglitz, 1974) or from other existing mod-

\footnotetext{
${ }^{10}$ If risk aversion decreases very quickly then it can happen that the optimal incentives increase with land fertility. However, we won't forget this case and show why it seems empirically inconsistent.
} 
els explaining tenancy contracts (Allen and Lueck, 1993).

Among the few studies on sharecropping caring about land quality, Ai et al. (1996) and Shaban (1987) include soil type and irrigation characteristics as explanatory variables to control for this kind of heterogeneity. In a transaction costs model with risk neutrality, Allen and Lueck (1992, 1993, 1996) point out the importance of the difference between farmer's perceived cost of land and its true cost. Using US data on agricultural contracts, they find that the probability of a sharecropping contract increases with the possibility of soil overuse by the farmer. Actually, cultivating row crops (such as corn) is more likely to induce excessive tilling which raises production in the short run but also leads to wind erosion, nutrient depletion and loss of moisture in the fields. On the other hand, irrigation is negatively related to the probability of sharecropping because irrigated land cannot be overused by the farmer. The econometric study of Allen and Lueck may suffer from endogeneity biases but it remains very insightful on the various factors determining tenancy forms. Except the papers of Allen and Lueck, empirical studies about sharecropping generally rely on data on tenants' behavior, and very few use data on landowners. We want to assess the relationship between land quality, production technology (depending on the cultivated crop) and contract by looking at landowner's decisions.

\subsection{Features of the surveyed rural area}

The Philippines data are drawn from a survey conducted by IFPRI and RIMC ${ }^{11}$ in the South Bukidnon Province of Mindanao. The sample consists in 448 households from ten villages ${ }^{12}$. Information is available on land tenure and land ownership, demographic characteristics, consumption and nutrition, asset ownership, off farm labor supply. Table 2 gives descriptive statistics of the variables. Each household was interviewed four times at four month intervals. A remarkable feature of these data is that an estimate by the owner of the value of each plot under each tenancy status is available. As shown by Bouis and Haddad (1990), land contracts between landlords and tenants are frequent in this rural area. It is to be noted that the Philippines land reform requiring the transformation of share tenancy to leasehold tenancy has been slow to implement and its application is very disparate across islands of the archipelago. Otsuka (1991) studies the consequences of the land reform decree of 1972 in Luzon and Panay Islands during the late seventies and the eighties. In Mindanao, its implementation happened much more later.

\footnotetext{
${ }^{11}$ International Food Policy Research Institute (Washington D.C.) and Research Institute for Mindanao Culture (Xavier University, Cagayan de Oro, Philippines).

${ }^{12}$ The municipalities are Valencia, Maramag, Kalilangan, Quezon, Don Carlos, Kadingilan, Kitao-tao, Dangcagan, Kibawe and Damulog.
} 
In particular, it had not yet been implemented at the time of the survey (1984-1985) in the Bukidnon region. The frequency of share tenancy in our sample also proves it.

\section{TABLE 2 HERE}

In this Philippines region, land transactions are rare and access to credit is almost impossible. In our sample, average owned land areas over all households are small (about 2.11 hectares by household or 0.26 hectares by person) and more than $57 \%$ of households are landless. The average owned area of landowners is more than 6.1 hectares. Moreover the average population density in the rural area studied is 149 inhabitants by $\mathrm{km}^{2}$ so that land is a scarce factor of production. There are spot markets for wage labor. In the contractual relationship, land being scarce while labor is abundant, landowners have monopsony power on the labor market and monopoly power on the land market. The assumption that landlords are much less risk averse than tenants can be supported by the fact that, in the surveyed area, most landlords own several plots of land rented out at fixed rent or on a share basis and moreover the average real income per capita of tenants and wage laborers is half that of households who own some plot of land (P27.7 against P51.4 per week). Landlords are really richer than leasing in tenants. These descriptive features support the use of a partial equilibrium analysis and the Principal-Agent framework.

Besides, Bouis and Haddad (1990) report that land fertility is an important factor in the determination of yields and agricultural incomes. They report that, according to a very large majority of peasants, land fertility decreased over the 1960's to the 1980's, and that corn yields had dramatically fallen due to fertility decrease. Consequently, agricultural incomes fell and almost all landowners were aware of this problem. Maintaining land quality is a sensitive issue. Land value clearly depends on its fertility. It seems legitimate to consider that the management of the fertility of the land is an important issue in the economic and organizational choices of landowners. Sharecropping is practiced using different production shares. In the empirical analysis, we have to pool all sharecropping contracts in the same category because the data do not provide the share rates for rented out plots of land. Thanks to those reported only for the rented in plots of land, we know however that three prevalent sharing rules are used $1 / 4,1 / 3$ and $1 / 2$ for the sharecropper ${ }^{13}$. We study the leasing out behavior of landowners to test our model against possible alternatives. We only distinguish between two systems of leasing out:

\footnotetext{
${ }^{13}$ If the land value variable were also available for rented in plots of land, we could also test some predictions of the model using these contracts and the more detailed information on sharing rules.
} 
fixed rent contracts and sharecropping contracts because we cannot take into account the value of the share ratios. A few observations on landowners could not be used because of inconsistent responses (nine cases). According to Bouis and Haddad (1990), three main crops are grown in the Philippines area studied: corn (dry), sugar and rice (generally using irrigation systems).

The theoretical model developed above considers the case of short term contracts only. Though long term contracts would mitigate the conflict of interest between parties in the land maintenance. However, the terms of the contracts often change but we do not know if it is a renegotiation with the same tenant or if the tenant has changed. For example, during the survey, the frequency of modified sharecropping contracts per year was equal to $52 \%$ and the frequency of modified fixed rent contracts was equal to $47 \%$. Unfortunately, we do not have the duration of contracts in our data. However, these large rates are likely to reflect that contracts are generally short term even if we cannot strictly control for the heterogeneity of contracts lengths in the estimations.

\subsection{Incentives, land value and cropping system}

In the case of corn, incentives to produce are bad for land quality while they are not of much importance in the production of rice or sugar. Then, the model predicts that incentives must be smaller for corn production and that for corn, a larger output share should be given to the tenant when the land quality is better.

The value of each plot is evaluated by the landowner (the land value per hectare is used). We test whether the likelihood of fixed rent versus share contracts is increasing with land value using a Probit specification (some preliminary non parametric tests of independence of the distribution of contracts among the land value quantile strongly reject the independence meaning that the contract choice is actually correlated with land value). The increasing relationship between $v(x)$ and $x$ allows to implement the empirical tests with the land value instead of the unobserved fertility index without modifying the predicted signs of coefficients.

\section{TABLE 3 HERE}

As shown in Table 3, in the decision of landlords, a sharecropping contract is more likely when corn is produced than for rice or other productions (the reference crop is sugar and other crops). This result is consistent with the prediction that in the case of corn production the risk of soil exploitation by the renter leads the landowner to propose a less incentive contract (sharecropping against fixed rent). For better lands, the probability of fixed rent rather than 
share-tenancy increases. As the contract choice may depend also on landowner's risk preferences, we introduce some observable characteristics which are likely to be correlated with risk aversion in order to control for this heterogeneity. As exogenous agricultural risk could be different between areas because of climatic and other environmental differences, we included village dummies in all the probit regressions. Several specification tests like testing for omitted variables, homoscedasticity ${ }^{14}$ have been made (Dubois, 1998a) and allowed to validate the estimation. Moreover, estimations of finite sample bias with bootstrap and indirect inference techniques showed that the inference is robust.

Crop specific effects

Conditional, on the technology, if the production effort is damaging for land, as commonly admitted for corn production, then the optimal share of production should be strictly smaller than one and be increasing with land quality. As the production function and fertility dynamics depend on cultivated crops, we analyze the contract choice by decomposing the land value with crop dummies. As shown, the likelihood of a fixed rent contract against sharecropping is lower for corn production than for rice or sugar production and is higher for higher land values.

Is there a bias from the endogeneity of crop choices?

It could be argued however that as the crop cultivated on the leased out plot is a decision variable for landowners or farmers, there is some endogeneity bias in the estimates of Table 3 . To check if the endogeneity of crop choices actually biases the coefficients, we test statistical exogeneity. The test consists in recasting the model in a two dimensional one.

In a first step, one implements a Lagrange Multiplier test $(\xi)$ of no correlation between crop choice $C_{i}$ and contract choice $y_{2 i}$ including exogenous "instrumental" variables $z_{i}$ in the crop determination. This step tests the lack of simultaneous equation bias in the contract choice. In a second step, we test the validity of instruments by another score test $(\zeta)$ of nullity of the coefficients of the instrumental variables in the contract equation i.e. we test the exclusion of these $z_{i}$ from the contract choice because they could be omitted variables in the contract choice. This step is an over-identifying restrictions test. However, if we do not want to exclude arbitrarily some exogenous variables of one or another equation of the bivariate discrete choice model of contract and crop, then its identification relies on the normality assumption of residuals. Consequently, the test of exclusion of some "instruments" in the crop choice equation relies implicitly

\footnotetext{
${ }^{14}$ Assuming that residuals could depend on a set of exogenous variables $z$, we can write $\operatorname{Var}(\eta)=(\exp (\mu z))^{2}$ in the latent model $y_{2 i}^{*}=x_{i} \gamma+\eta_{i}$. We can make a Lagrange Multiplier test of $\mu=0$. We made several heteroscedasticity tests showing that we cannot reject homoscedasticity with respect to variables such as owned land area, owned total land value, household size.
} 
on normality unless we exclude arbitrarily some other exogenous variables which is not testable (unless, again, we trust identification from normality). Implementing the tests either by relying on normality or by excluding some exogenous explanatory variables, which did not appear to have a significant effect (in the estimation relying on normality), we found the same qualitative results $^{15}$. The orthogonality tests presented are those excluding the distances from the contract choice equation to estimate the crop choice equation. The corresponding overidentifying test shows that distance variables are not omitted in the contract choice equation when considering that crops are truly statistically exogenous in the contract equation. Of course, this part of the test assumes either that the bivariate probit discrete choice is correctly identified (normality of error terms leading to accept erroneously exogeneity) or that some exogenous variables are excluded from one equation at least (which is not testable without relying on normality but is considered to provide a more robust identification of the bivariate probit model).

The results of these orthogonality tests for corn are in Table 3 and show that we cannot reject the hypothesis of no simultaneity bias. The same tests made in the case of rice allow us not to reject the null hypothesis with even more confidence.

The distance variables which strongly determine the crop grown are also included in the contract equation as shown in the first two columns of Table 3 with or without the crop dummy variables. In both cases, their appear non significant and do not remove the land value effect. We have no structural model that gives a meaning to the sign of variable coefficients in the auxiliary equation for crop but we can give some interpretation. Actually, it seems that the crop cultivated depends on location (distances are proxy variables). It can be a consequence of the difference in profitability or riskiness of corn production versus sugar production which depends on the location of landowners. Actually, sugarcane is more profitable than corn (see Bouis and Haddad, 1990) only if cultivated near the sugar mill.

Landowners unobserved specific effects

In relation to the model, heterogeneity in risk aversion or in time preferences leads theoretically to different choices resulting from the trade off between risk sharing, production and fertility investment. In order to account for the heterogeneity of landowners, we introduce some landowners specific effects in the latent model writing: $a_{i j t}=\alpha x_{j t}+a_{i}+u_{i j t}$ where $a_{i j t}$ is the incentive slope of the contract given by landlord $i$ on plot $j$ at time $t$. The observation of different contracts on different plots of a same landowner allows us to compute a "within-landowner

\footnotetext{
${ }^{15}$ I thank Andrew Foster for leading me to clarify this point.
} 
between-plots" estimate. Supposing that the specific effect is randomly normally distributed in the population of landowners, we can estimate a random effects probit model. Because time variation is not sufficient for the algorithm to converge, we cannot estimate the random effects probit with period-specific effects and only time dummies are used. Table 3 shows that the empirical results remain robust to these unobserved landlords' specific effects.

Finally, we deduce that the canonical model is insufficient to explain the empirical findings whereas our model is consistent with empirical regularities (as long as the assumptions of the theoretical model are valid).

\subsection{Simultaneous choice to lease out and of contract}

Another economic and econometric contribution is that we are able to avoid the sample selection bias that plagues studies on tenancy choices. Contracting choices are generally explained on the basis of observed sets of contracts only. The choice set of landowners is broader and the contract choice is simultaneous to the choice to contract. As there is no reason to a priori think that they are independent, the contract choice equation may suffer from a selection bias problem. Formally, denoting $y_{1 i}^{*}$ the latent variable governing the decision to lease out a land plot: $y_{1 i}^{*}$, the landowner decides to lease out land if $y_{1 i}^{*}>0$. He chooses between fixed rent or share tenancy according to $y_{2 i}^{*}$ and $y_{2 i}=1_{y_{2 i}^{*}>0}$ is one for fixed rent and zero for share tenancy. Writing the full econometric model with the bivariate censored form: $y_{1 i}=1_{y_{1 i}^{*}>0}, y_{2 i}=1_{y_{2 i}^{*}>0}$ observed if

$y_{1 i}=1$ where the latent model is $\left\{\begin{array}{l}y_{1 i}^{*}=x_{i} \beta+\varepsilon_{i} \\ y_{2 i}^{*}=x_{i} \gamma+\eta_{i}\end{array}\right.$ with $\left(\varepsilon_{i}, \eta_{i}\right)^{\prime} \hookrightarrow N(0,0,1,1, \rho)$, we can test if the correlation $\rho$ is zero. Under the null that error terms of both probit regressions are uncorrelated, one can run two independent probit regressions and then perform a score test of $H_{0}=\{\rho=0\}$. The score test statistics for each specification show that we cannot reject $H_{0}$. However, we know from Andrews (1989) that the power of our test statistic may be low and that even a relatively high correlation might stay undetected. Therefore, we estimate by maximum likelihood the censored bivariate model. Results of the censored bivariate model with different specifications (with or without additional explanatory variables) do not allow to identify always precisely the correlation parameter but give all the same evidence with respect to the coefficients of interest. The standard deviation of the correlation coefficient is sometimes large and estimating the inverse power function $\pi($.$) of \rho$ (Andrews, 1989) with $\pi(0.95)=3.60 \times \widehat{s e_{\rho}}$ and $\pi(0.5)=1.96 \times \widehat{s e_{\rho}}$, we can see that for large intervals of correlation values we have a high probability of type II error and there is no range of possible values for the correlation parameter for which the test 
would have high power. However, the less imprecise results presented in Table 4 are consistent with the predictions of the model. The estimated correlation parameter $\rho$ shows that there is some selectivity bias in the probit regressions on the sample of landowners who lease out some land ${ }^{16}$. Results found previously on the determinants of the contract choice carry over and are robust to the inclusion of land left fallow by landowners in the non leasing out choice for a plot.

\section{TABLE 4 HERE}

An important issue is to determine how the probability to lease out a plot of land evolves according to its value. A probit estimation of the decision to delegate the use of land on the land value per hectare shows it is increasing with land value (controlling for other explanatory variables: land area owned, owned assets, corn and rice dummies, household size, education of father and mother, village and time dummies). This result may suggest that the efficiency loss induced by delegation never offsets the increased cost induced by self cultivation. However, estimation results using different specifications (logarithmic and with powers of land value per hectare) in Table 5 show different results.

\section{TABLE 5 HERE}

The maximum of the parabolic approximation is at a land value of $5557 \mathrm{P} / \mathrm{h}$. (corresponding to the $78^{t h}$ percentile of the distribution of plot values per hectare). In the first specification one can say that the probability for a landowner to cultivate himself a plot of land is strictly decreasing with its fertility. With the second specification, the probability for a landowner to cultivate a plot of land instead of delegating its use is $U$ shaped with respect to the fertility level ${ }^{17}$. In the first model, the inefficiency loss of land delegation never dominates the cost difference between the landowner and the peasant. In the second, the efficiency loss dominates the effect of the cost difference for high land values.

In order to test between these two specifications to know which one is the closest to the true model, we implement the inference procedure of Vuong (1989) which derives some likelihood ratio tests allowing to test between strictly non nested or overlapping models. The test consists in two steps, the first tests if the variance of the likelihood ratio statistic is significantly different

\footnotetext{
${ }^{16}$ Even, if in our particular case, the selectivity bias appeared to have a non significant effect on the contract choice equation, there can be no presumption that it is a general result on contract choice equations. It remains a critical point to be checked for other econometric studies.

${ }^{17}$ Taking into account unobserved specific effects of landowners that could represent heterogeneity in the cost of effort, we estimated the random effect probit model of choice to lease out. It gave the same results with respect to the $U$ shape and similar coefficients.
} 
from zero meaning that the two models are distinguishable. In the case of Table 5, the variance is $n \widehat{\omega}_{n}^{2}=9.79$. Its asymptotic distribution is a weighted sum of chi-squares which weights are the 47 eigenvalues ${ }^{18}$ of a variance covariance matrix $\widehat{W}_{n}$ and a Monte Carlo simulation shows that the statistic corresponds to the $94 \%$ critical level. This allows to infer that models are distinguishable. The second step tests between both non nested models thanks to the likelihood ratio statistic $n^{-1 / 2} L R_{n}\left(\widehat{\theta}_{n}, \widehat{\gamma}_{n}\right) / \widehat{\omega}_{n}=-6.55$ which is far below the $1 \%$ significance level of the standard normal distribution. Therefore we can reject the null hypothesis that both models are equivalent in favor of $G_{\gamma}$ being better than $F_{\theta}$. Implementing the test with adjusted LR statistics corresponding to Akaike and Schwarz information criteria, we obtained the same result (we found respectively -6.24 and -5.45 ).

The test shows that the second model performs better than the first. We conclude that the probability that a landowner delegates the use of a plot of land is indeed inverse $U$ shaped i.e. it is increasing below some fertility level and decreasing above. It means that for high land values, the efficiency loss of delegation is too large and the landowner prefers to cultivate himself the plot of land even if he has a higher marginal cost of effort. This empirical result is inconsistent with the assumption that agents are risk neutral because of the presence of an efficiency loss. It confirms the presence of risk aversion and rejects a pure "transaction cost" approach where people contracts would be explained only by the land conservation argument without risk aversion behavior. Therefore, the joint empirical findings on contract incentives and on the leasing out decision seem to be inconsistent with the pure risk sharing model but not with our model ${ }^{19}$.

\section{Nonparametric Estimation}

In order to check whether the empirical $U$ shape function, found for the probability to lease out with respect to land value per hectare, is not due to the parametric assumption of error terms and the quadratic specification on land value, we estimate the probability of leasing out land non parametrically. Writing $y_{1 i}^{*}=r\left(x_{i}\right)+\varepsilon_{i}$ and $y_{1 i}=1_{y_{1 i}^{*}>0}$, we estimate $\widehat{r}(x)$ with a Nadaraya-Watson kernel estimator $\widehat{r}(x)=\left(\sum_{i=1}^{n} y_{1 i} K\left(\frac{x_{i}-x}{h}\right)\right) /\left(\sum_{i=1}^{n} K\left(\frac{x_{i}-x}{h}\right)\right)$. We can also include other explanatory variables $z$ and estimate $\widehat{r}(x, z)$ with multivariate kernels.

\footnotetext{
${ }^{18}$ Eigenvalues range from -1.27 to 0.57 .

${ }^{19}$ In the canonical model with an agent having a very decreasing risk aversion, the optimal incentives can be increasing with fertility. But then we would expect the probability of delegation to be increasing for high fertility levels where the optimal contract is nearly a fixed rent and the second best reaches the first best. On the contrary, the probability of delegation is decreasing at high fertility levels meaning that this very special case of utility shape could not explain the empirical results in the canonical model.
} 
The figure 1 shows the estimated regression function ${ }^{20}$ of the decision to contract on the land value per hectare $(/ 1000 P)$. However, does this $U$ shape persist when other explicative variables are introduced? Including them sequentially, we can estimate and plot the regression functions.

\section{FIGURE 1 HERE \\ FIGURE 2 HERE}

The three dimensional plots (figure 2) show the estimates of the regression functions when another variable is included. Globally, the inverse $U$ shape of land value remains in all cases (the variables included are total owned area, household size, household members by owned hectare of land, education of father, education of mother, age of household head). These empirical facts confirm the results obtained when we control for all variables simultaneously in the parametric regressions.

\section{Conclusion and development policy implications}

This Principal-Agent model of moral hazard with a stock variable in the production function allowed us to show the importance of land fertility in the determination of the optimal contract. The optimal contract depends on the technology of production and the land fertility dynamics as well as risk aversion. We derived an endogenous land value function and testable implications about the form of the contract. Because of the long term - short term conflict of objectives and the damaging effect on fertility of land overuse, the second best contract is a sharing arrangement even if agents are risk neutral. This is an original point of this model in the literature on land tenancy. Optimal incentives depend on the possibility of land overuse and on its fertility level. The model explains why a landowner uses different contracts on different plots of land. The leasing out decision of a landowner depends on the difference in cost of effort between the landowner and the peasant and the efficiency loss due to the delegation to a risk averse agent. From the empirical study, the most important results are that the pure risk sharing model and the pure transaction cost approach are rejected in this Philippines area while our model integrating both trade-off seems to be empirically consistent. Landlords choose more incentive contracts (fixed rent versus share tenancy) for more valuable plots of land and less incentive ones when cropping practices, such as for corn, induce more land overuse. The probability of leasing out a plot of land is inverse $U$ shaped with respect to land value. Using these Philippines

\footnotetext{
${ }^{20}$ Estimation with Gaussian kernel and bandwidth $h=1.14$. Results are similar with Epanechnikov kernel.
} 
data, the predictions of our model are empirically consistent, a fact explained by our model and showing that risk sharing cannot be ruled out.

Finally, the soil quality appears to be an important economic factor in the choice of tenancy agreements. This is to be considered for policy design with respect to land conservation, production levels and efficiency of agricultural organizations. Actually, it is often argued that development policies recommending to prevent sharecropping contracts in favor of renting at fixed rate must be accompanied by measures allowing to improve access to insurance because sharecropping provides risk sharing to the tenant. However, we showed that even with risk neutrality a sharecropping contract can be optimal if commitment failure prevents the credible use of long term contracts leading to a conflict between short term and long term interests between the landlord and the tenant. Leasing at fixed rent can have deleterious effects on long term production because of the impoverishment of land. Therefore, policies promoting the enforcement of long term contracts may be necessary in addition to giving access to insurance. Social institutions able to improve the enforcement of long term contracts with formal agreements would likely incite landlords to use long term agreements. Moreover, our model shows that the decisions of landowners to lease out land being also endogenous, the regulation of contracting institutions may have an impact not only on contracting practices but also on leasing out decisions of landowners who may prefer to manage land cultivation themselves (hiring laborers) instead of leasing out at fixed rent to a tenant. Reforms of contracting institutions may then have consequences on access to land via the land rental market. For example, if long term commitment is not credible, preventing sharecropping may impose the use of short term fixed rent contracts giving too much land overuse incentives to be used by landowners who may prefer either to manage cultivation themselves or to leave land fallow. An important implication for development policy design when land is unequally distributed in quantities and in qualities.

\section{Appendix}

\subsection{Proof of proposition 2.2}

In the case of perfect information, the proof is straightforward and consists in defining an operator $T$ relating the expected value at the end of the period and the expected value at the beginning of the period. The value function is the fixed point of $T$. It is increasing and concave because $T$ is a contraction mapping which maps the space of increasing concave functions onto itself. We now turn to the imperfect information case. 
In the case of risk neutrality, the value function is the first best one and the proof is straightforward. However, the method (Stokey, Lucas, and Prescott, 1989), consists in defining an operator $T$ which is shown to be a contraction mapping with a unique fixed point which is increasing (and concave) because $T$ maps the set of continuous (and concave) functions onto itself. In the risk neutral case, $T$ is defined by $T w(x)=\underset{a>0}{\operatorname{Max}} f(x, e(x, a))-C(e(x, a))-\bar{U}+\delta E w(\varepsilon g(x, e(x, a)))$

$$
=f\left(x, e\left(x, a^{*}(x)\right)\right)-C\left(e\left(x, a^{*}(x)\right)\right)-\bar{U}+\delta E w\left(\varepsilon g \left(x, e\left(x, a^{*}(x)\right)\right.\right.
$$

where $a^{*}(x)=\underset{a}{\arg \max } f(x, e(x, a))-C(e(x, a))-\bar{U}+\delta E w(\varepsilon g(x, e(x, a)))$ and $e(x, a)=\underset{e}{\arg \max } a E[\nu f(x, e)]-C(e)$. To prove that the solution of the functional equation is an increasing function, it needs to show that if $w$ is increasing, then $T w$ is also. The same applies for the concavity. With the envelope theorem $\frac{\partial T w}{\partial x}(x)=f_{x}+\delta E \varepsilon w^{\prime} g_{x}+e_{x}\left(f_{e}-C_{e}\right)+\delta E \varepsilon w^{\prime} e_{x} g_{e}=$ $f_{x}+\delta E \varepsilon w^{\prime} g_{x}$ because $a f_{e}=C_{e}$ and $(1-a) f_{e}+\delta E \varepsilon w^{\prime} g_{e}=0$. If As $w^{\prime}>0$, then $\frac{\partial T w}{\partial x}(x)>0$ because $f_{x}>0$ and $g_{x}>0$.

\subsection{Proof of proposition 2.3}

The Principal chooses the transfer function $\tau(y)=(1-a) y-b$ that maximizes his expected utility $E[(1-a) y-b+\delta v(z)]$ under the Individual Rationality constraint, and the following Incentive Compatibility constraint: $e \in \underset{e}{\arg \max } E U(a y+b)-C(e)$.

Lemma 5.1. Pareto efficiency is achieved under imperfect information if and only if the Agent is risk neutral.

Denoting $e^{*}, \tau^{*}$ the first best effort and transfer. To implement the first best effort $e^{*}$, the contract must both respect the individual rationality constraint and give some incentives making $\tau($.$) depend on production. If e^{*}$ is implemented at the same cost than in the first best i.e. $E[a y+b]=\tau^{*}$, then, by Jensen's inequality and the concavity of the utility function: $E U(a y+b)-C\left(e^{*}\right) \leq U\left(\tau^{*}\right)-C\left(e^{*}\right)=\bar{U}$. The participation constraint is verified only if $U$ is linear.

By the differentiable approach, the incentive constraint becomes $a E \nu U^{\prime} f_{e}(x, e)=C_{e}(e)$ and a straightforward derivation gives the following lemma:

Lemma 5.2. In the risk neutral case, the IC constraint defines an Agent's best answer effort supply $e(a, x)$, differentiable such that $e_{x}=-a f_{e x} M$ and $e_{a}=-f_{e} M$ with $M^{-1}=a f_{e e}-C_{e e}<$ 0 . Hence $e_{a}>0$ and $f_{e x} e_{x}>0$.

This lemma allows us to say that effort is strictly increasing with incentive power, $a$, whereas it is strictly increasing or decreasing with fertility $x$ as fertility and labor are complementary or 
substitutes in the production function. The first order condition of the maximization program directly gives the proposition.

\subsection{Proof of proposition 2.2}

We need to prove that if $w$ is increasing then $T w$ is also increasing where $T w(x)=\max _{a}$ $(1-a) E[\nu f(x, e(x, a))]-b(x, a)+\delta E w(\varepsilon g(x, e(x, a)))$. With the envelope theorem, $\frac{\partial T w}{\partial x}=$ $(1-a)\left[f_{x}+e_{x} f_{e}\right]-\left(\frac{\partial b}{\partial x}\right)_{\bar{U}}+\delta E \varepsilon w^{\prime}\left(g_{x}+g_{e} e_{x}\right)$. Differentiating the equation defining $b(x, a)$ we have $\left(\frac{\partial b}{\partial x}\right)_{\bar{U}}=-a f_{x} \frac{E \nu U^{\prime}}{E U^{\prime}}$. So $\frac{\partial T w}{\partial x}=f_{x}\left(1-a\left(1-\frac{E \nu U^{\prime}}{E U^{\prime}}\right)\right)+(1-a) e_{x} f_{e}+\delta E \varepsilon w^{\prime} g_{x}$ with $(1-a) f_{e}=\left(1-\frac{E \nu U^{\prime}}{E U^{\prime}}\right) \frac{f}{e_{a}}-E \varepsilon w^{\prime} g_{e}$ by proposition 2.3. Moreover, $e_{a}=\frac{E \nu U^{\prime}+a\left(E \nu^{2} U^{\prime \prime}-E \nu U^{\prime \prime} E \nu U^{\prime} / E U^{\prime}\right) f}{C_{e e}-a E \nu U^{\prime} f_{e e}-a^{2} E \nu^{2} U^{\prime \prime} f_{e}^{2}} f_{e}, e_{x}=a \frac{E \nu U^{\prime} f_{e x}+a\left(E \nu^{2} U^{\prime \prime}-E \nu U^{\prime \prime} E \nu U^{\prime} / E U^{\prime}\right) f_{e} f_{x}}{C_{e e}-a E \nu U^{\prime} f_{e e}-a^{2} E \nu^{2} U^{\prime \prime} f_{e}^{2}}$ and $C_{e e}-$ $a E \nu U^{\prime} f_{e e}-a^{2} E \nu^{2} U^{\prime \prime} f_{e}^{2}>0$. We know that $0<\frac{E \nu U^{\prime}}{E U^{\prime}}<1$. Hence supposing $E \nu^{2} U^{\prime \prime}-$ $E \nu U^{\prime \prime} E \nu U^{\prime} / E U^{\prime}$ is positive or small in magnitude if negative, we have $e_{a}>0$ and $e_{x}$ of the sign of $f_{e x}$ like in the risk neutral case. If $f_{e x} \geq 0$ then $a \leq 1, e_{x} \geq 0$ and $\frac{\partial T w}{\partial x} \geq 0$. Also we have, $\frac{\partial T w}{\partial x}=$ $f_{x}+\frac{\left(1-E \nu U^{\prime} / E U^{\prime}\right) a E \nu U^{\prime}\left[f_{e x} f-f_{e} f_{x}\right]}{E \nu U^{\prime}+a\left(E \nu^{2} U^{\prime \prime}-E \nu U^{\prime \prime} E \nu U^{\prime} / E U^{\prime}\right) f}+\delta E \varepsilon w^{\prime} g_{x} \geq 0$ if $e_{a} \geq 0$ and $f_{e x} f-f_{e} f_{x} \geq 0$ i.e. $\frac{\partial}{\partial x}\left(f_{e} / f\right) \geq$ 0 . For Cobb-Douglas production functions we have $f_{e x} f-f_{e} f_{x}=0$. For the concavity, we need that $w$ concave implies that $T w$ is also. As $f_{x x} \leq 0, g_{x x} \leq 0, w^{\prime \prime} \leq 0$, and $\frac{\partial^{2} T w}{\partial x^{2}}=f_{x x}+$ $\delta E \varepsilon w^{\prime} g_{x x}+\delta E \varepsilon w^{\prime \prime} g_{x}^{2}+\left[\delta E \varepsilon w^{\prime \prime} g_{x} g_{e}+\delta E \varepsilon w^{\prime} g_{e x}+f_{e x}\right] e_{x}+\frac{\partial}{\partial x}\left[\frac{\left(1-E \nu U^{\prime} / E U^{\prime}\right) a E \nu U^{\prime}\left[f_{e x} f-f_{e} f_{x}\right]}{E \nu U^{\prime}+a\left(E \nu^{2} U^{\prime \prime}-E \nu U^{\prime \prime} E \nu U^{\prime} / E U^{\prime}\right) f}\right]$. Hence assuming that third order effects are negligible i.e. that second order effects dominate higher order ones, $\frac{\partial^{2} T w}{\partial x^{2}} \simeq f_{x x}+\delta E \varepsilon w^{\prime} g_{x x}+\delta E \varepsilon w^{\prime \prime} g_{x}^{2} \leq 0$.

\subsection{Proof of proposition 2.4}

Assume there is a given value function $w$. The value of the first best and second best problems are the fixed point of the operators $T_{f b}$ and $T_{s b}$ defined by : $T_{f b} w(x)=M_{e} a x f(x, e)-C(e)-$ $\bar{U}+\delta E w(\varepsilon g(x, e))$ and $T_{s b} w(x)=\underset{a}{M a x}(1-a) E[\nu f(x, e(x, a))]-b(x, a)+\delta E w(\varepsilon g(x, e(x, a)))$ where $b(x, a)$ allows to satisfy the individual rationality constraint. First, $T_{f b} w(x)-T_{s b} w(x) \geq$ 0 (equals zero when the Agent is risk neutral). Then we have (see appendix 5.1 and 5.3): $\frac{\partial}{\partial x} T_{f b} w(x)=f_{x}\left(x, e_{f b}\right)+\delta E \varepsilon w^{\prime}\left(\varepsilon g\left(x, e_{f b}\right)\right) g_{x}\left(x, e_{f b}\right)$ and $\frac{\partial}{\partial x} T_{s b} w(x)=f_{x}\left(x, e_{s b}\right)$ $+\delta E \varepsilon w^{\prime}\left(\varepsilon g\left(x, e_{s b}\right)\right) g_{x}\left(x, e_{s b}\right)$ with assumption 1b. $w$ being concave and $f_{e x} \geq 0, g_{e} \leq 0$, $g_{e x} \geq 0$, we have: $\frac{\partial}{\partial x}\left[T_{f b} w(x)-T_{s b} w(x)\right]>0$ if $e_{f b}>e_{s b}$ and the opposite if $e_{f b}<e_{s b}$. In some very extreme cases, the Agent's risk aversion can be such that $e_{f b}<e_{s b}$ implying that $\frac{\partial}{\partial x}\left[T_{f b} w(x)-T_{s b} w(x)\right]<0$. However, in most cases, it is likely that $e_{f b}>e_{s b}$ because in the second best the landlord needs to share risk with the Agent giving less incentives than that of 
the first best.

\subsection{Proof of proposition 2.5}

Assume there is a given value function $w$. In the risk neutral case, the value of self cultivation and of delegation (which is that of the first best since we are in the risk neutral case) are the fixed point of operators $T_{s c}$ and $T_{f b}$ defined by $T_{i} w(x)=\underset{e_{i}}{M a x}\left[f\left(x, e_{i}\right)-C_{i}\left(e_{i}\right)-\bar{U}_{i}+\delta E w\left(\varepsilon g\left(x, e_{i}\right)\right)\right]$ for $i=s c, f b$, where $C_{f b}$ and $C_{s c}$ are respectively the Agent's and Principal costs of effort. By the envelope theorem $\frac{\partial}{\partial x} T_{i} w(x)=f_{x}\left(x, e_{i}\right)+\delta E \varepsilon w^{\prime}\left(\varepsilon g\left(x, e_{i}\right)\right) g_{x}\left(x, e_{i}\right)$. The implemented effort are defined by $f_{e}\left(x, e_{i}\right)+\delta E \varepsilon w^{\prime}\left(\varepsilon g\left(x, e_{i}\right)\right) g_{e}\left(x, e_{i}\right)=C_{i}^{\prime}\left(e_{i}\right)$. As $\frac{\partial}{\partial e}\left[f_{e}(x, e)+\delta E \varepsilon w^{\prime} g_{e}(x, e)\right]$ $=f_{e e}(x, e)+\delta E \varepsilon^{2} w^{\prime \prime} g_{e}^{2}(x, e)+\delta E w^{\prime} g_{e e}(x, e)<0$ (because $\left.f_{e e}<0, g_{e e}<0, w^{\prime \prime}<0, w^{\prime}>0\right)$ and $C_{f b}^{\prime}()<$. $C_{s c}^{\prime}($.$) , we deduce that e_{s c}<e_{f b}$. With $f_{e x} \geq 0, g_{e} \leq 0, g_{e x} \geq 0, w$ increasing concave, we have: $\frac{\partial}{\partial x}\left[T_{f b} w(x)-T_{s c} w(x)\right]>0$.

\subsection{Comparative statics}

- Canonical Model [1]: trade-off between production incentives and risk sharing (Stiglitz, 1974): $a^{*}=1-\left(1-E \nu U^{\prime} / E U^{\prime}\right) f / e_{a} f_{e}$.

- Encompassing Model [2]: this model with moral hazard on land fertility use (proposition 2.3): $a^{*}=1-\left(1-E \nu U^{\prime} / E U^{\prime}\right) f / e_{a} f_{e}+E \varepsilon \delta v^{\prime} g_{e} / f_{e}$.

Risk neutrality

Assuming risk neutrality for both contractors, the model of pure moral hazard in production would predict the choice of fixed rent contracts whatever the land value (the empirical evidence is obviously contrary to this prediction whereas our model remains consistent with data even under risk neutrality of agents). As a benchmark, we remark that the production-land value trade-off is monotone with respect to land fertility:

Assumption 6 The function $g$ governing fertility dynamics and land value are such that $\frac{\partial^{2}}{\partial e \partial x}(E \varepsilon v \circ g) \geq 0$.

It is always the case with $v$ increasing concave and assumption $3\left(g_{e x} \geq 0\right)$, but the condition $\partial^{2} / \partial e \partial x(f+E \varepsilon \delta v \circ g) \geq 0$ is sufficient and less restrictive.

Assumption 7 The function $f$ is such that $0 \leq f_{e x} \leq\left(\frac{C_{e e} f_{e}}{C_{e}}-f_{e e}\right) \min \left\{\frac{g_{x}}{-g_{e}}, \frac{g_{e x}}{-g_{e e}}\right\}$.

Proposition 5.3. In the risk neutral case, under assumptions 6 and $7, a(x)$ is an increasing function. 
Proof: With risk neutrality, the first best can be achieved. Writing $H(e, x)=f(x, e)-$ $C(e)-\bar{U}+E \delta v(\varepsilon g(x, e)), e^{*}(x)=\underset{e}{\arg \max } H(e, x)$ and the incentive slope allowing to implement the first best effort $e^{*}$ is defined by the incentive constraint $a^{*}(x) f_{e}=C_{e}$. According to the envelope theorem $\forall x, \frac{\partial H}{\partial e}\left(e^{*}(x), x\right)=0$ and $\frac{\partial e^{*}(x)}{\partial x}=-H_{e x} / H_{e e}$. As, $H_{e}=$ $f_{e}-C_{e}+E \varepsilon \delta v^{\prime} g_{e}$. Therefore, $H_{e e}=f_{e e}-C_{e e}+E \varepsilon \delta v^{\prime} g_{e e}+E \varepsilon^{2} \delta v^{\prime \prime} g_{e}^{2}<0$ and $H_{e x}=f_{e x}+$ $E \varepsilon^{2} \delta v^{\prime \prime} g_{e} g_{x}+E \varepsilon \delta v^{\prime} g_{e x}$. If $g_{e x} \geq 0$, then $H_{e x}>0$ with $f_{e x}>0$ and $v$ increasing concave, $g$ increasing in $x$ and decreasing in $e$. However, $g_{e x} \geq 0$ is not necessary and $E \varepsilon^{2} v^{\prime \prime} g_{e} g_{x}+$ $E \varepsilon v^{\prime} g_{e x}=\frac{\partial^{2}}{\partial e \partial x}(E \varepsilon v \circ g) \geq 0$ is sufficient. In these cases, we have $\frac{\partial e^{*}(x)}{\partial x} \geq 0$. Then $\frac{\partial a^{*}(x)}{\partial x}=$ $\frac{\left(C_{e e} f_{e}-f_{e e} C_{e}\right) e_{x}-f_{e x} C_{e}}{f_{e}^{2}}>0$ if $f_{e x}=0$. If $f_{e x}>0$, we must check that the direct incentive effect will not dominate the substitution disincentive effect of an increase of fertility. We have $\frac{\partial a^{*}(x)}{\partial x}=\frac{C_{e e} f_{e x}(1-a) f_{e}+\delta\left(C_{e e} f_{e}-f_{e e} C_{e}\right)\left[E \varepsilon v^{\prime} g_{e x}+E \varepsilon^{2} v^{\prime \prime} g_{e} g_{x}\right]+f_{e x} C_{e} \delta\left[E \varepsilon v^{\prime} g_{e e}+E \varepsilon^{2} v^{\prime \prime} g_{e}^{2}\right]}{-f_{e}^{2}\left[f_{e e}-C_{e e}+E \varepsilon \delta v^{\prime} g_{e e}+E \varepsilon^{2} \delta v^{\prime \prime} g_{e}^{2}\right]}$ where the denominator is negative. If $f_{e x}=0, \frac{\partial a^{*}(x)}{\partial x}>0$. As $C_{e e} f_{e x}(1-a) f_{e}>0,\left(C_{e e} f_{e}-f_{e e} C_{e}\right)<0,\left(E \varepsilon v^{\prime} g_{e x}+\right.$ $\left.E \varepsilon^{2} v^{\prime \prime} g_{e} g_{x}\right)>0$ and $E \varepsilon v^{\prime} g_{e e}+E \varepsilon^{2} v^{\prime \prime} g_{e}^{2}<0$. Supposing that $\left(C_{e e} f_{e}-f_{e e} C_{e}\right) g_{e x}+f_{e x} C_{e} g_{e e}>0$ and $\left(C_{e e} f_{e}-f_{e e} C_{e}\right) g_{x}+f_{e x} C_{e} g_{e}>0$ is sufficient. We must check that $f_{e x}$ is not too large, i.e. $f_{e x}<$ $\min \left[\left(f_{e e}-C_{e e} f_{e} / C_{e}\right) \frac{g_{x}}{g_{e}},\left(f_{e e}-C_{e e} f_{e} / C_{e}\right) \frac{g_{e x}}{g_{e e}}\right]$ because $g_{e e} \leq 0$ and $g_{e x} \geq 0$.

Risk sharing in the canonical model

First, by a continuity argument, the proposition established in the case of risk neutrality can be extended to the case of risk averse tenants having a small risk aversion. In the general case, the analysis is too complicated to derive exact implications and we need to make some approximations. The Principal's revenue is $\max _{a} R(a, x)$ with $R(a, x)=(1-a) f(x, e(x, a))-b(x, a)$ where $b(x, a)$ is implicitly defined by the individual rationality constraint and $e(x, a)$ by the incentive compatibility constraint. According to the envelope theorem $\forall x, \frac{\partial R}{\partial a}\left(a^{*}(x), x\right)=0$ and $a^{* \prime}(x)=-R_{a x} / R_{a a}$. As $R_{a a}<0$, the sign of $a^{* \prime}(x)$ depends on $R_{a x}=-f_{x}-f_{e} e_{x}+$ $(1-a) f_{e x} e_{a}+f_{e} e_{a x}-b_{a x}$. As $b_{x}=-a f_{x} \frac{E \nu U^{\prime}}{E U^{\prime}}, b_{a x}=\left(-f_{x}-a f_{e x} e_{a}\right) \frac{E \nu U^{\prime}}{E U^{\prime}}-a f_{x} \frac{\partial}{\partial a}\left(\frac{E \nu U^{\prime}}{E U^{\prime}}\right)$, $R_{a x}=-f_{x}\left(1-\frac{E \nu U^{\prime}}{E U^{\prime}}-a \frac{\partial}{\partial a}\left(\frac{E \nu U^{\prime}}{E U^{\prime}}\right)\right)-f_{e} e_{x}+\left(1-a\left(1-\frac{E \nu U^{\prime}}{E U^{\prime}}\right)\right) f_{e x} e_{a}+f_{e} e_{a x} \approx-f_{x}\left(1-\frac{E \nu U^{\prime}}{E U^{\prime}}\right)-f_{e} e_{x}$ if third order effects are neglected because $0<\frac{E \nu U^{\prime}}{E U^{\prime}}<1$. Therefore $a^{* \prime}(x) \leq 0$.

Another argument is to say that the slope elasticity of production will be smaller with better land quality i.e. that the direct land productivity increase dominates all other effects on effort's productivity and incentives. Moreover, we can presume that the increase of the insurance effect will be dominated by the elasticity of production. This is likely to be true when risk aversion 
does not decrease too fast ${ }^{21}$. Then the following term $\left(1-E \nu U^{\prime} / E U^{\prime}\right) / \eta_{a}^{f}$ will be non decreasing with $x$ meaning $a^{*}$ will decrease with $x$ in the canonical model.

For Constant Absolute Risk Aversion utilities, we could approximate $E \nu U^{\prime} / E U^{\prime} \simeq 1-a f \sigma_{A}$ Var $\nu$ where $\sigma_{A}$ is the coefficient of absolute risk aversion. Then $\frac{1-a^{*}}{a^{*}} \simeq \frac{\sigma_{A} V a r \nu f^{2}}{e_{a} f_{e}}$ and $\frac{f^{2}}{e_{a} f_{e}}$ can be supposed non decreasing with $x$ because the increase of production squared is likely to dominate all other effects. Therefore, $\frac{1-a}{a}$ being decreasing in $a, a(x)$ is a decreasing function of $x^{22}$.

In our dynamic model we can easily see that $\frac{-g_{e}}{a f_{e}} E \varepsilon v^{\prime}$ will be decreasing with $x$ for a sufficiently concave value function. In this case $a(x)$ will increase or decrease according to which term will dominate ${ }^{23}$.

\section{References}

Ackerberg D. and Botticini M., 2000, Endogenous Matching and the Empirical Determinants of Contract Form, mimeo

Ackerberg D. and Botticini M., 2000, The Choice of Agrarian Contracts in Early Renaissance Tuscany: Risk Sharing, Moral Hazard, or Capital Markets Imperfections? Explorations in Economic History, 37, 241-257

Ai C., Arcand J. L., Ethier, 1996, Moral Hazard and Marshallian Inefficiency: Evidence from Tunisia, CRDE, Cahier 0896

Allen D. and Lueck D., 1992, Contract Choice in Modern Agriculture: Cash Rent versus Crop Share, Journal of Law \&3 Economics, 35, 397-426

Allen D. and Lueck D., 1993, Transaction Costs and the Design of Cropshare Contracts, Rand Journal of Economics, 24, 1, 78-100

Allen D. and Lueck D., 1996, The Transaction Cost Approach to Agricultural Contracts, in Agricultural Markets: Mechanisms, Failures, Regulations, Ed. D. Martimort North Holland

Andrews D., 1989, Power in Econometric Applications, Econometrica, 57, 5, 1059-1090

Baker G. P., 1992, Incentive Contracts and Performance Measurement, Journal of Political Economy, 100, 3, 598-614

Bardhan P., 1984, Land, Labor and Rural Poverty: Essays in Development Economics, Oxford

\footnotetext{
${ }^{21}$ Actually, it is possible that, for very decreasing risk aversions, $1-E \nu U^{\prime} / E U^{\prime}$ will decrease sufficiently to compensate the production increase and lead to an increasing $a(x)$.

${ }^{22}$ A simple simulation with $U=\log$ (Constant Relative Risk Aversion utility), $f(x, e)=x^{.4} e^{.3}, c(e)=e^{2}$, and $\nu$ of mean one (production uncertainty multiplicative factor) following a $\beta$-regularized cumulative distribution $H(\nu)=\frac{\Gamma(8)}{\Gamma(4)^{2}} \int_{0}^{\nu / 2} t^{3}(1-t)^{3} d t$ where $\Gamma(z)=\int_{0}^{\infty} t^{z-1} e^{-t} d t$ show that $a(x)$ is decreasing.

${ }^{23}$ If the landlord is also risk averse, we can see that if he is sufficiently less risk averse than the tenant then we have the same implications. It can be seen as a result of a continuity argument.
} 
University Press

Bose G., 1993, Interlinked Contracts and Moral Hazard in Investments, Journal of Development Economics, 41, 247-273

Bouis H., Haddad L., 1990, Agricultural Commercialization, Nutrition, and the Rural Poor, Linne Rienner Publishers

Braverman A., Stiglitz J., 1986, Cost-Sharing Arrangements under Sharecropping: Moral Hazard, Incentive Flexibility and Risk, American Journal of Agricultural Economics, 68, 642-652

Chiappori P. A., Macho I., Rey P., Salanié B., 1994, Repeated Moral Hazard: The Role of Memory, Commitment, and the Access to Credit Markets, European Economic Review, 38, 1527-1553 Dutta B., Ray, D., Sengupta K., 1989, Contracts with Eviction in Infinitely Repeated PrincipalAgent Relationships, in The Theory of Agrarian Institutions Ed. P. Bardhan, Oxford Clarendon Dubois P., 1998a, Moral Hazard, Land Fertility and Sharecropping in a Rural Area of the Philippines, mimeo, WP CREST 9930

Dubois P., 1998b, Multitask Moral hazard, Incentive Contracts and Land Value, mimeo CREST Eswaran M. and Kotwal A., 1985, A Theory of Contractual Structure in Agriculture, American Economic Review, 75, 3, 352-367

Fudenberg D. Holmstrom B. and Milgrom P., 1990, Short-Term Contracts and Long-Term Agency Relationships, Journal of Economic Theory, 51, 1-31

Hayami Y. and Otsuka K, 1993, The Economics of Contract Choice An Agrarian Perspective, Oxford Clarendon Press

Hart O. and Holmstrom B., 1987, The Theory of Contracts, in Advances in Economic Theory edited by T. Bewley, Cambridge University Press

Holmstrom B. and Milgrom P., 1987, Aggregation and Linearity in the Provision of Intertemporal Incentives, Econometrica, 55, 303-328

Johnson D. G., 1950, Resource Allocation under Share Contracts, Journal of Political Economy, $58,111-123$

Laffont J. J., Matoussi M. S., 1995, Moral Hazard, Financial Constraints and Sharecropping in El Oulja, Review of Economic Studies, 62, 381-399

Lambert R. A., 1983, Long Term Contracts and Moral Hazard, Bell Journal of Economics, autumn, 14, 441-452

Newbery D., Stiglitz J. , 1979, Sharecropping, risk sharing and the importance of imperfect information, in Risk, Uncertainty and Agricultural Development Ed. Roumasset J., Boussard J. 
M., Singh, I.

Otsuka K. 1991, Determinants and consequences of land reform implementation in the Philippines, Journal of Development Economics, 35, 339-355

Otsuka K., Chuma H., Hayami Y., 1992, Land and Labor Contracts in Agrarian Economies: Theories and Facts, Journal of Economic Literature, 30, 1965-2018

Otsuka K., Chuma H., Hayami Y., 1993, Permanent Labour and Land Tenancy Contracts in Agrarian Economies: An Integrated Analysis, Economica, 60, 57-77

Radner R., 1985, Repeated Principal-Agent Games with Discounting, Econometrica, 53, 1173-98 Rao C. H., 1971, Uncertainty, Entrepreneurship and Sharecropping in India, Journal of Political Economy, 79, 3, 578-595

Rey P. and Salanié B., 1990, Long-Term, Short-Term and Renegotiation: On the Value of Commitment in Contracting, Econometrica, 58, 597-619

Rey P. and Salanié B., 1996, On the Value of Commitment with Asymmetric Information, Econometrica, 64, 1395-1414

Rogerson W. P., 1985, Repeated Moral Hazard, Econometrica, 53, 1, 69-76

Roumasset, J., 1984, Explaining Patterns in Landowner Shares: Rice, Corn, Coconut, and Abaca in the Philippines, 82-95, chap. 4 in Contractual Arrangements, Employment, and Wages in Rural Labor Markets in Asia

Rubinstein A. and Yaari M. E., 1983, Repeated Insurance Contracts and Moral Hazard, Journal of Economic Theory, 30, 74-97

Shaban R., 1987, Testing Between Competing Models of Sharecropping, Journal of Political Economy, 95, 5, 893-920

Singh N., 1989, Theories of Sharecropping, in The Theory of Agrarian Institutions Ed. Bardhan, P., Oxford Clarendon Press

Stiglitz J. E., 1974, Incentives and Risk Sharing in Sharecropping, Review of Economic Studies, 41, 2, 219-255

Stokey N., Lucas R. and Prescott E., 1989, Recursive Methods in Economic Dynamics, Harvard University Press.

Vuong Q. H., 1989, Likelihood Ratio Tests for Model Selection and Non-Nested Hypotheses, Econometrica, 57, 2, 307-333

Weitzman M., 1980, Efficient Incentive Contracts, Quarterly Journal of Economics, 94, 719-730 Williamson O., 1985, The Economic Institutions of Capitalism, New York: Free Press 
Table 1: Comparison of predictions

\begin{tabular}{|c|c|c|c|c|}
\hline \multirow{3}{*}{$\begin{array}{c}\text { Agent's } \\
\text { Preferences }\end{array}$} & \multicolumn{2}{|c|}{ Pure risk sharing model } & \multicolumn{2}{|c|}{ Present model } \\
\hline & Risk & Risk & Risk & Risk \\
\hline & Neutral & Averse & Neutral & Averse \\
\hline $\begin{array}{l}\text { Leasing Out Choice } \\
\qquad \mathrm{d}(\mathrm{x})\end{array}$ & increasing & $\begin{array}{c}\text { increasing } \\
\text { or decreasing }\end{array}$ & increasing & $\begin{array}{c}\text { increasing } \\
\text { or decreasing }\end{array}$ \\
\hline $\begin{array}{l}\text { Optimal Share } \\
\mathrm{a}(\mathrm{x})\end{array}$ & 1 & $\begin{array}{c}<1 \text { and } \\
\text { decreasing }\end{array}$ & $\begin{array}{c}<1 \text { and } \\
\text { increasing }\end{array}$ & $\begin{array}{c}\text { increasing } \\
\text { or decreasing }\end{array}$ \\
\hline & (1) & $(2)$ & (3) & (4) \\
\hline
\end{tabular}

Table 2: Descriptive Statistics

\begin{tabular}{lrrr}
\hline \hline Variable & Average & Std. Dev. & Obs. \\
\hline Land area owned & 2.11 & 3.88 & 1792 \\
Mother's education (years) & 6.25 & 2.72 & 448 \\
Father's education (years) & 5.70 & 3.03 & 448 \\
Household size & 6.81 & 2.47 & 448 \\
Value of Productive assets & 4709 & 9133 & 448 \\
Value of Non productive assets & 14166 & 35334 & 448 \\
Age of Household head & 37.1 & 8.25 & 448 \\
Land value per hectare & 4173 & 4785 & 1229 \\
Corn dummy & 0.54 & 0.49 & 1229 \\
Rice dummy & 0.08 & 0.27 & 1229 \\
Sugar dummy & 0.33 & 0.47 & 1229 \\
\hline \hline
\end{tabular}




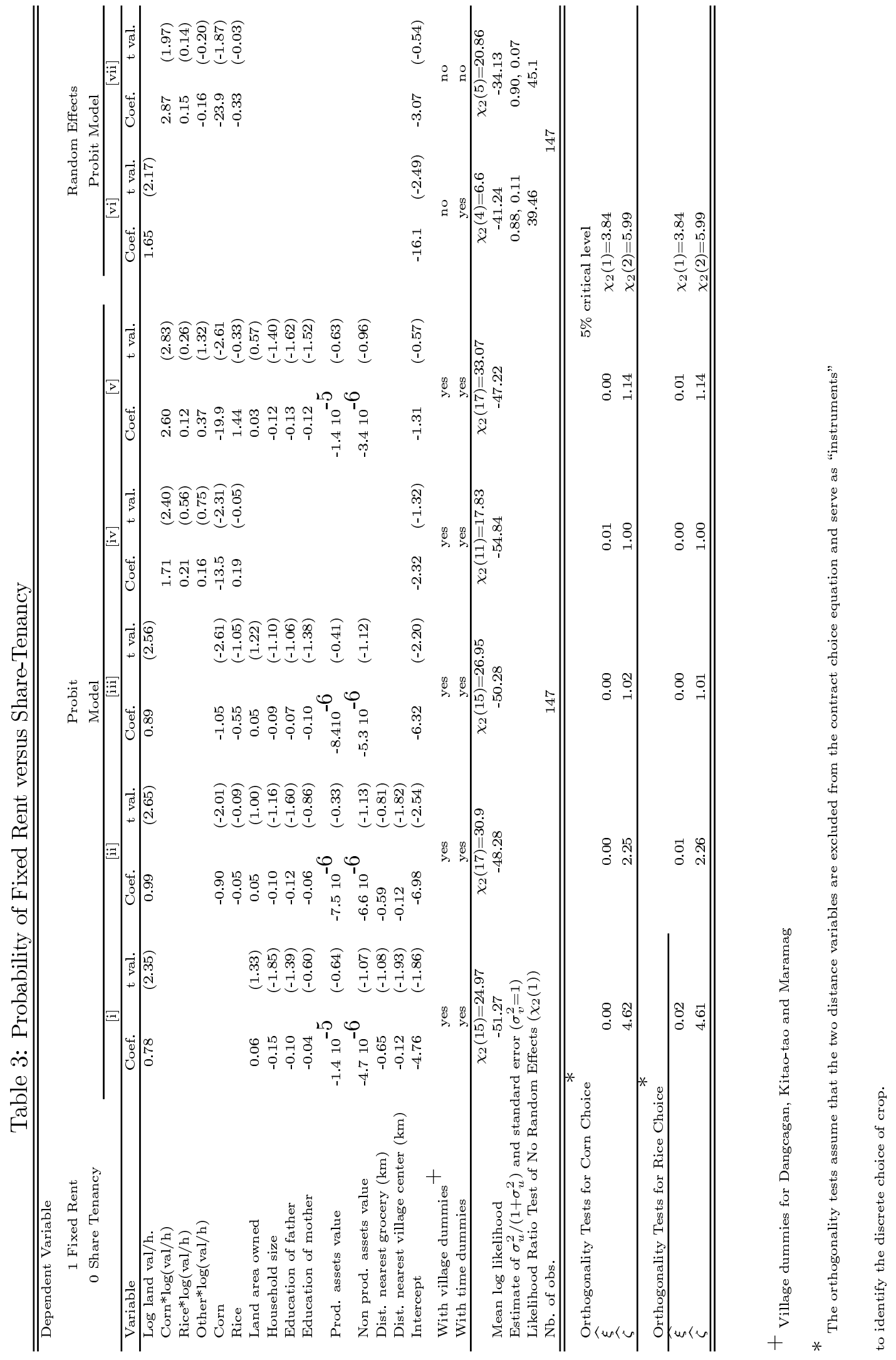




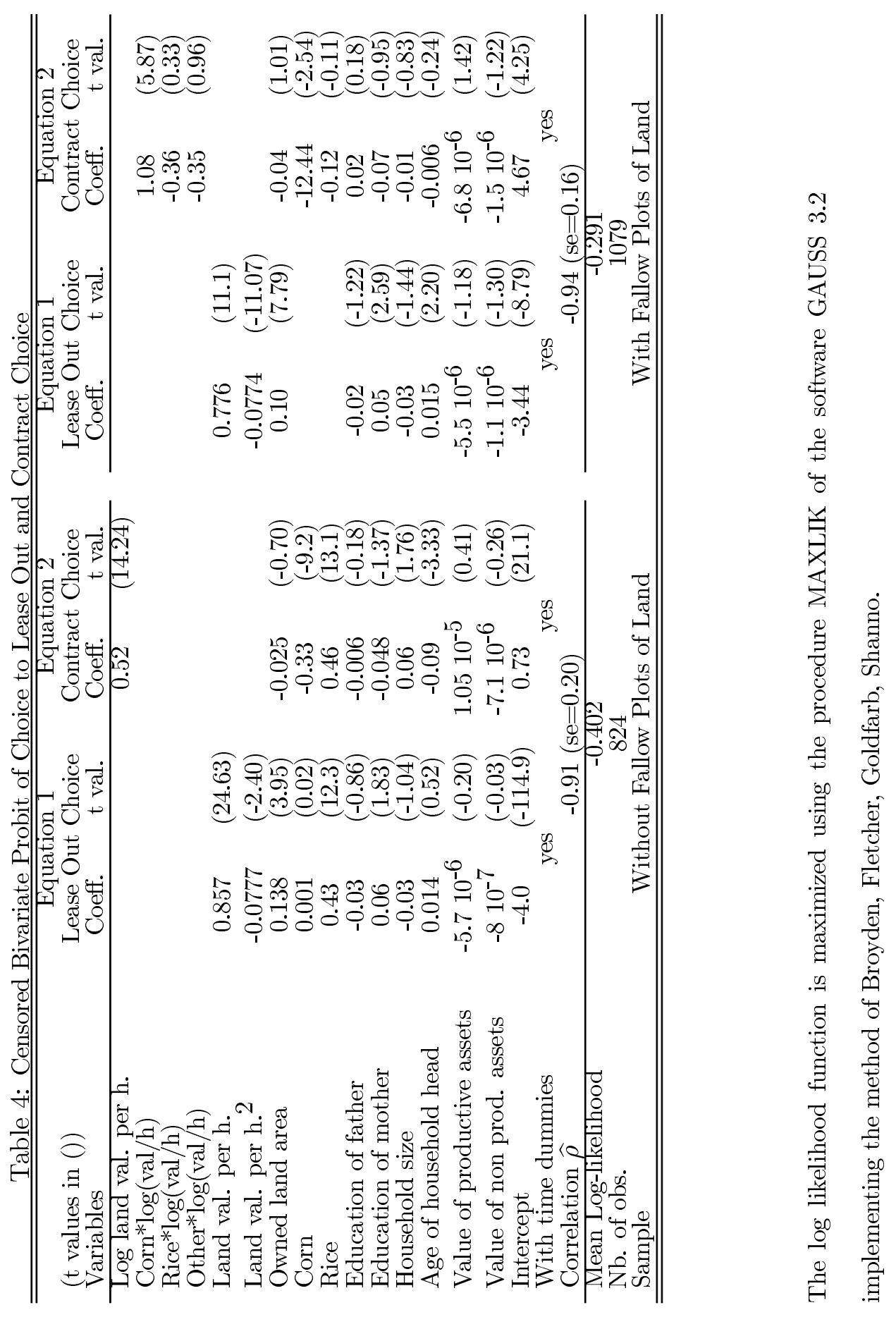


Table 5: Non Nested Models of Choice to Contract

\begin{tabular}{|c|c|c|c|c|}
\hline \multicolumn{5}{|c|}{$\begin{array}{l}\text { Probit of Choice to Lease Out (1) vs Self Cultivation (0) } \\
\end{array}$} \\
\hline \multirow[b]{2}{*}{ Variables } & \multicolumn{2}{|c|}{$\left[F_{\theta}\right]$} & \multicolumn{2}{|c|}{$\left[G_{\gamma}\right]$} \\
\hline & Coeff. & (t val.) & Coeff. & (t val.) \\
\hline $\log (\mathrm{val} / \mathrm{h})$ & 0.37 & $(6.71)$ & & \\
\hline$(\mathrm{val} / \mathrm{h})$ & & & 0.87 & $(9.53)$ \\
\hline$(\mathrm{val} / \mathrm{h})^{2}$ & & & -0.078 & $(-8.36)$ \\
\hline Owned land area & 0.18 & $(5.84)$ & 0.22 & $(6.76)$ \\
\hline Owned land area ${ }^{2}$ & -0.003 & $(-2.71)$ & -0.0042 & $(-3.24)$ \\
\hline Corn & 0.06 & $(0.51)$ & 0.019 & $(0.16)$ \\
\hline Rice & 0.27 & $(1.44)$ & 0.29 & $(1.58)$ \\
\hline Household size & -0.03 & $(-1.51)$ & -0.047 & $(-1.84)$ \\
\hline Age of household head & 0.021 & $(2.86)$ & 0.018 & $(2.46)$ \\
\hline Education of father & -0.03 & $(-1.37)$ & -0.029 & $(-1.31)$ \\
\hline Education of mother & 0.08 & $(3.20)$ & 0.067 & $(2.45)$ \\
\hline Value of productive assets & $-8.110^{-6}$ & $(-1.70)$ & $-110^{-5}$ & $(-2.16)$ \\
\hline Value of non productive assets & $-3.710^{-7}$ & $(-0.42)$ & $-3.210^{-7}$ & $(-0.35)$ \\
\hline Intercept & -5.91 & $(-9.57)$ & -4.54 & $(-10.1)$ \\
\hline \multicolumn{5}{|l|}{ With 8 village dummies } \\
\hline \multicolumn{5}{|l|}{ With time dummies } \\
\hline Mean Log-likelihood & \multicolumn{2}{|c|}{-0.346} & \multirow{2}{*}{\multicolumn{2}{|c|}{-0.310}} \\
\hline Nb. of obs. & & & & \\
\hline \multirow[t]{2}{*}{$\begin{array}{l}\text { Vuong Test } \\
\end{array}$} & \multicolumn{3}{|c|}{$\mathrm{n} \widehat{\omega}_{n}^{2}=9.79$} & (Weighted $\chi_{2}$ ) \\
\hline & \multicolumn{3}{|c|}{$\mathrm{n}^{-1 / 2} \mathrm{LR}_{n}\left(\widehat{\theta}_{n}, \widehat{\gamma}_{n}\right) / \widehat{\omega}_{n}=-6.55$} & $(\mathrm{~N}(0,1))$ \\
\hline
\end{tabular}


Non Parametric Regression with Confidence Interval Bandwith $=1.14$

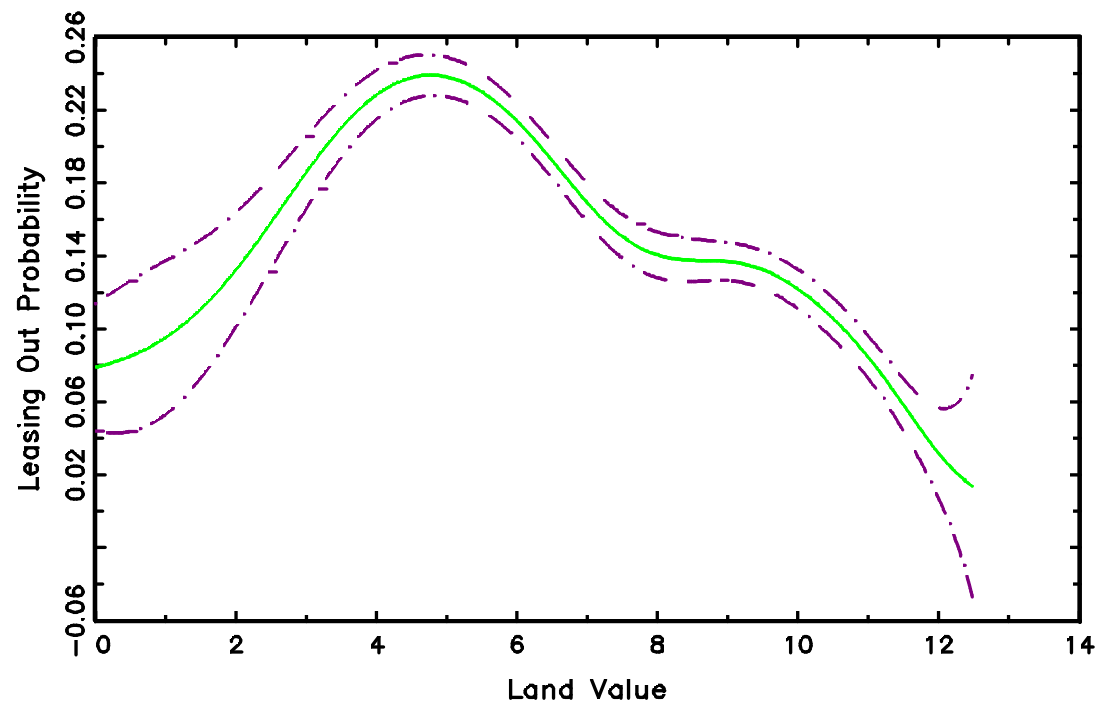

Figure 1: Probability of Delegation with respect to Land Value 

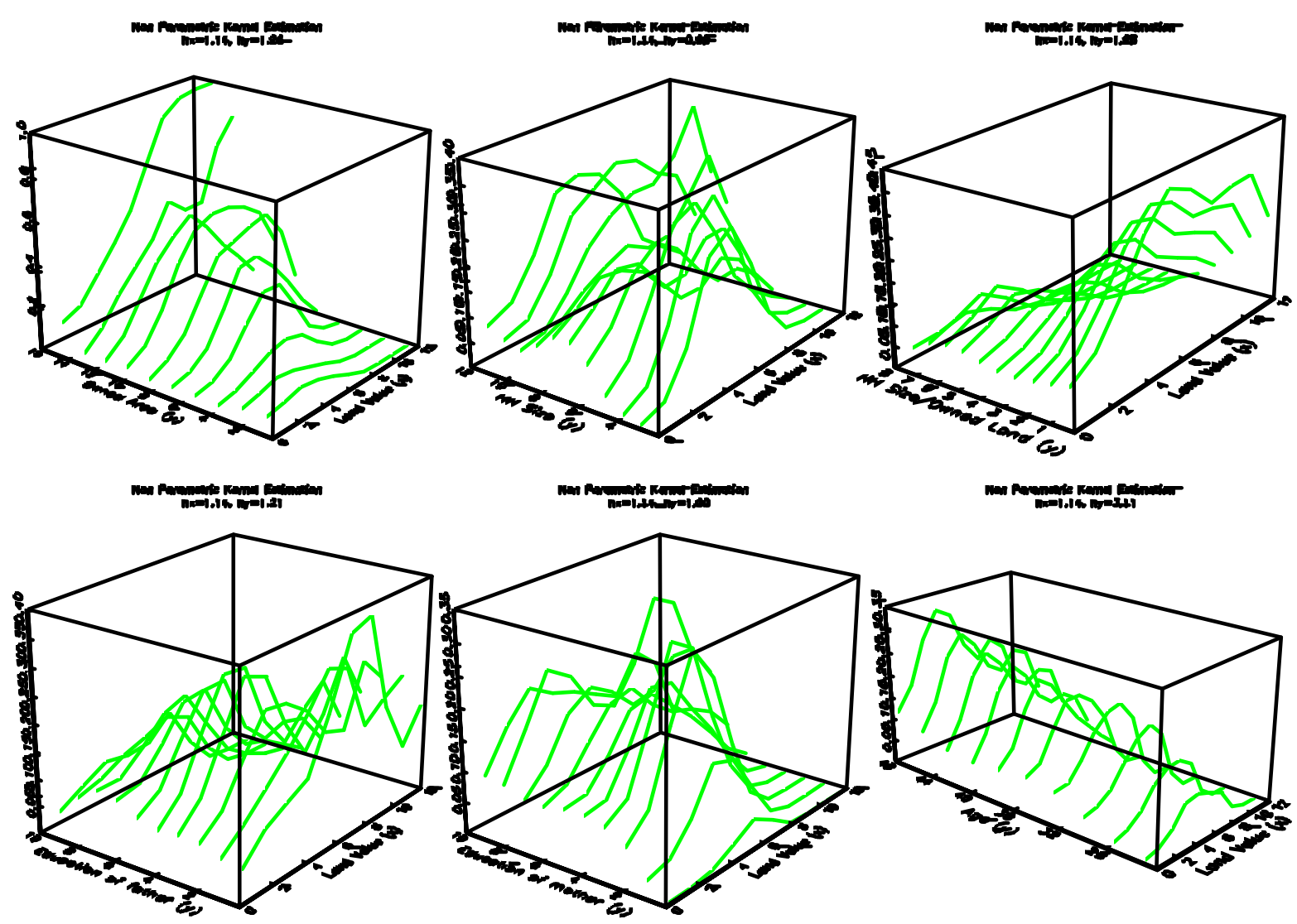

Figure 2: Non Parametric Estimation of Probability of Delegation 